\title{
MODEL FOR CLINICAL MANAGEMENT USING BODY MASS INDEX OF DIABETES PATIENTS
}

\section{A. O. ABIDOYE AND E. T. JOLAYEMI}

(Received 4, September 2008; Revision Accepted 4, May 2009)

\begin{abstract}
The importance of body weight of patients on admission in the management of diabetes was studied using Data from the University of llorin Teaching Hospital on the management of diabetes. Weight was partitioned into three groups: underweight, normal weight and overweight. Three models were used for comparison: a model that used weight of diabetes patient as a covariate, a second that used both weight and admitting blood sugar reading of diabetes patients as covariates and the third separate models for each of the three weight groups of diabetes patient as covariate.

Results showed that the latter model performed better than the earlier two models that were considered on this study based on the adjusted $\mathrm{R}^{2}$. Also our finding revealed that the minimum expected days to bring down the blood sugar level to threshold value are: 8 days for underweight, 12 days for normal weight and 27 days for overweight.
\end{abstract}

KEYWORDS: BMI, weight, admitting blood sugar reading, obesity, repeated measures, covariate, non-linear model, correlated errors.

\section{INTRODUCTION:}

Obesity is a nutritional disorder that is characterized by excessive accumulation of fat in any or all of the subcutanenus tissues, omentum and viscera and muscles. Obesity in diabetes is common in the developed world because of gross overeating and eating of high fat and refined carbohydrate foods. Its high prevalence in developing countries is associated with poverty, ignorance about good nutrition and ideal body weight and consumption of excessive amount of carbohydrate. See Kwawukume and Emuveyan(2002). Body mass index (BMI) is used to measure obesity and because it is caused as described above it may be a factor in developing diabetes. It is the most appropriate measure for assessing weight change since weight readily changes more rapidly than height. Therefore in an attempt to determine how an erstwhile high blood sugar level can be brought down to the threshold value, this work introduces BMI into the follow-up study of inpatient diabetes patients as a covariate.

In this paper, the methodology of analysis is presented in section two. In section three we use the re-analyzed of UITH (University of llorin Teaching Hospital) data and end this paper with a conclusion in section four.

\section{METHODOLOGY:}

Let $y_{i j t}$ be the response observed on the $i^{\text {th }}$ subject in group $\mathrm{j}$ at time $\mathrm{t}, \mathrm{i}=1,2, \ldots, n_{j}, \mathrm{j}=1, \ldots, \mathrm{J}$ and $\mathrm{t}=$ $1,2, \ldots, T_{i}$. Let $X^{\prime}=\left(X_{1}, \ldots, X_{k}\right), \sum n_{j}=n$. be the vector of covariates. Using the model which is an extension of that used by Abidoye and Jolayemi (2005), (2006) and Jolayemi and Abidoye (2005) that introduced some covariates into the system of equations the general model is given as

$E\left(y_{i j}\right)=f_{1}\left(X_{1}, \theta_{1}\right)+f_{2}\left(t, \theta_{2}\right)$

where $f_{1}$ represents the function for the covariate and $f_{2}$ the function representing the model for the repeated observations. $f_{1}$ and $f_{2}$ may be linear or non-linear, although $f_{1}$ is usually linear, see example from Draper \& Smith (1966). The Expected Mean (EM) or Newton Raphson algorithm may be used to estimate $\theta^{1}=\left(\theta_{1}^{1}, \theta_{2}^{1}\right)$ as described explicitly in Abidoye and Jolayemi (2006) using Least Square Estimation Methodology. Further explanation on curve fitting can also be found in McCullagh \& Nelder (1989), Jolayemi (1995), Oyejola \& Jolayemi(1997).

The first model to be considered in this study is fully discussed in Abidoye and Jolayemi (2006), where the covariate is admitting blood sugar reading. In this connection the model is generally given by

$E\left(y_{i j}\right)=f_{1}\left(X_{1}, \theta\right)+f_{2}\left(t, \theta_{2}\right)$.

Next let $X_{1}$ represent weight and $X_{2}$ initial blood sugar reading on admission.

For the diabetes data,

$f_{1}\left(X_{1}, \theta\right)+f_{2}\left(X_{2}, \theta_{2}\right)=\theta\left(X_{1 j}-\bar{X}_{1}\right)+\lambda\left(X_{2 j}-\bar{X}_{2}\right)$

A. O. Abidoye, Department of Statistics, University of Ilorin, Ilorin, Nigeria.

E. T. Jolayemi, Department of Statistics, University of Ilorin, Ilorin, Nigeria. 
Where $\mathrm{j}=1,2,3$ represents the three BMI groups. $X_{1 i}$ and $X_{2 i}$ represent weight and admitting blood sugar readings respectively, $\bar{X}_{1}=\sum_{j} X_{1 i} / n_{j} \quad$ and $\bar{X}_{2 .}=\sum_{j} X_{2 i} / n_{j}$ and $\quad \alpha_{j} \quad$ and $\quad \beta_{j t}$ represents parameter estimate in the model.

Obviously, because of the repeated nature of $y_{i j t}$, $\operatorname{cov}\left(y_{i j t,}, y_{i^{\prime} j^{\prime} t^{\prime}}\right) \neq 0$ to ensure errors.

Indeed, $\operatorname{cov}\left(y_{i t,} y_{i(t+j)}\right)=\sigma^{2} \rho^{j}$ is assumed and this was recognized and used in the analysis. If desirable, it is not difficult to partition the data according to the severity level of diabetes of the patient as adopted by Abidoye and Jolayemi (2006).

\section{RE- ANALYSIS OF DIABETES DATA:}

The body mass index was classified into three groups: underweight is measure $19.8 \mathrm{~kg} / \mathrm{m}^{2}$ and below (group1), normal weight is measure between 19.9 $29.9 \mathrm{~kg} / \mathrm{m}^{2}$ (group2) and overweight is measure above $30 \mathrm{~kg} / \mathrm{m}^{2}$ (group3) as reported by Kwawukume and Emuveyan(2002).

First, assume equation (2.2) and let weight be the covariate. Then

$E\left(y_{i t}\right)=\theta\left(X_{1 i}-\bar{X}_{1}\right)+e^{\alpha+\beta}$

where $\bar{X}_{1}$ is as defined earlier.

Table 3.1 is the ANOVA table arising from equation (3.1) providing an adjusted $R^{2}=0.632$, which is an improvement of above $10 \%$ in explained variability compared to the nonlinear model that does not consider any covariate. The estimates of the parameters are $\hat{\theta}=0.014 \pm 0.0021, \hat{\alpha}=2.432 \pm 0.036$ and $\hat{\beta}=-0.040$ \pm 0.0021 each of which is significant at $5 \%$ level.

Table 3.1: ANOVA table for equation (3.1) for the diabetes clinical management

\begin{tabular}{lcccc} 
Source & D.F & SS & MS & F \\
\hline Regression & 3 & 20345.63 & 6781.88 & 607.15 \\
Parameter estimate: & & & & \\
$\theta$ & 1 & 9748.95 & 9748.95 & 872.77 \\
$\alpha$ & 1 & 6358.01 & 6358.01 & 569.20 \\
$\beta$ & 1 & 4238.67 & 4238.67 & 379.47 \\
Error & 1063 & 11870.49 & 11.17 & \\
\hline
\end{tabular}

Total

$1066 \quad 32216.12$

Second, assume equation (2.1) is

$E\left(y_{i t}\right)=\theta\left(X_{1 i}-\bar{X}_{1}\right)+\lambda\left(X_{2 i}-\bar{X}_{2 .}\right)+e^{\alpha+\beta t}$

where $\bar{X}_{1}$ and $\bar{X}_{2}$. are as defined earlier.

Table 3.2 is the ANOVA table for equation (3.2) providing an adjusted $R^{2}=0.672$, which is an improvement of above $17 \%$ in explained variability to the

nonlinear model that does not consider the included covariates. The estimates of the parameters are

$\hat{\theta}=0.010 \pm 0.0001, \quad \hat{\lambda}=0.014 \pm 0.0022, \quad \hat{\alpha}=2.10$

\pm 0.000003 and $\hat{\beta}=-0.021 \pm 0.00013$

each of which is significant at $5 \%$ level.

Table 3.2: ANOVA table for equation (3.2) for the diabetes clinical management.

\begin{tabular}{lcccc} 
Source & D.F & SS & MS & F \\
Regression & 4 & 21635.22 & 5408.81 & 543.05 \\
\hline Parameter estimate: & & & & \\
$\theta$ & 1 & 7239.62 & 7239.62 & 726.87 \\
$\lambda$ & 1 & 6841.04 & 6841.04 & 686.85 \\
$\alpha$ & 1 & 4251.24 & 4251.24 & 426.83 \\
$\beta$ & 1 & 3303.32 & 3303.32 & 331.66 \\
Error & 1062 & 10580.90 & 9.96 & \\
\hline Total & 1066 & 32216.12 & & \\
\hline
\end{tabular}

Next, a further possible improvement for the re-analysis of the data is having the model given by

$E\left(y_{i t}\right)=\lambda\left(X_{2 i}-\bar{X}_{2}\right)+e^{\alpha_{1}+\beta t}$ 
arising from the gains observed in table 3.3 where $j=$ $1,2,3$ represent the three BMI groups using initial blood sugar as the covariate and $\bar{X}_{2}$ is as defined earlier. The goodness-of-fit is assessed in table 3.3 with an adjusted $R^{2}=0.705$. The estimates of the parameters are $\hat{\lambda}=$
$0.032 \pm 0.0004, \hat{\alpha}_{1}=2.40 \pm 0.0024, \hat{\alpha}_{2}=2.11 \pm 0.001$, $\hat{\alpha}_{3}=2.04 \pm 0.006, \hat{\beta}_{1}=-0.02 \pm 0.00017, \hat{\beta}_{2}=-0.010 \pm$ 0.0028 , and $\hat{\beta}_{3}=-0.04 \pm 0.00031$.

Table 3.3: ANOVA table for equation (3.3) using initial blood sugar as the covariate.

\begin{tabular}{lcccc} 
Source & D.F & SS & MS & F \\
Regression & 7 & 22721.84 & 3245.98 & 361.87 \\
\hline Parameter estimate: & & & & \\
$\lambda$ & 1 & 9824.06 & 9824.06 & 1095.21 \\
$\alpha$ & 3 & 7569.78 & 2523.26 & 281.30 \\
$\beta$ & 3 & 5328.00 & 1776.00 & 197.996 \\
Error & 1059 & 9494.28 & 8.97 & \\
\hline Total & 1066 & 32216.12 & & \\
\hline
\end{tabular}

Finally, a further possible improvement is to consider the model
$E\left(y_{i t}\right)=\theta_{j}\left(X_{2 i}-\bar{X}_{2}\right)+e^{\alpha_{j}+\beta \beta_{j} t}$

$$
\begin{aligned}
& 0.51 \pm 0.001, \quad \hat{\alpha}_{1}=2.64 \pm 0.05, \quad \hat{\theta}_{2}=0.21 \pm 0.007 \\
& \hat{\alpha}_{2}=2.49 \pm 0.03, \hat{\alpha}_{3}=2.04 \pm 0.006, \hat{\beta}_{1}=-0.06 \pm 0.005
\end{aligned}
$$$$
\text { Table (3.4) is the ANOVA table for equation (3.4) }
$$ providing an adjusted $R^{2}=0.764$ to assess goodness - of -fit. (This provided above $26 \%$ gain in explained variability). The estimates of the parameters are $\hat{\theta}_{1}=$ 
model. Nigerian Journal of Pure and Applied Science 10, 91-103

Kwawukume, E.Y and Emuveyan, E. E., 2002. Comprehensive Obstetrics in the Tropics. Asante and Hittscher Printing Press Limited.

Oyejola, B. A and Jolayemi, E. T., 1997. A comparison of some models for studying relationships of the sigmoid form. Nigerian Journal of Pure and Applied Science 31:193-198.

Mccullagh, P. AND Nelder, J. A., 1989. Generalized Linear Models. Chapman and Hall, New York. 